\title{
Edema, Enigma: 11 B-Hydroxysteroid Dehydrogenase Type 2 Inhibition by Sweetener "Stevia"
}

\author{
Salina Esmail ${ }^{1}$, Udaya M. Kabadi ${ }^{2,3}$ \\ ${ }^{1}$ Private Practice, Upland, USA \\ ${ }^{2}$ University of Iowa Hospitals and Clinics, Iowa City, USA \\ ${ }^{3}$ Des Moines University, Des Moines, USA \\ Email: ukabadi@gmail.com
}

Received May 8, 2012; revised June 11, 2012; accepted July 6, 2012

\begin{abstract}
Intrduction: Edema, Hypertension and Hypokalemia occur with inhibition of 11 B-Hydroxysteroid Dehydrogenase Type 2 (11B-HSD2) by chronic Licorice ingestion. However, a similar presentation following a chronic use of another commonly used sweetener "Stevia" is not reported. Objective: To document a first case report of a subject presenting with Edema, Prehypertension and Hypokalemia induced by 11B-HSD2 inhibition induced by chronic ingestion of sweetener stevia. Case Report: 32 year old Caucasian woman presented with generalized edema (feet, hands and face) of over 6 months. She was noted to also manifest Prehypertension $(138 / 88 \mathrm{mmHg})$ and Hypokalemia $(3.4 \mathrm{mM} / \mathrm{l})$. Laboratory tests revealed decline in serum aldosterone and plasma renin activity, an increase in plasma cortisol/cortisone ratio. On persistent interrogation, patient admitted to daily consumption of sweetener stevia for over 9 months. All the presenting manifestations resolved with normalization of the laboratory tests on withdrawal of stevia. Conclusion: This case report indicates that chronic ingestion of sweetener stevia may induce edema, hypertension and hypokalemia via reduced conversion of cortisol into cortisone by inhibition of 11 B-Hydroxysteroid Dehydrogenase Type 2.
\end{abstract}

Keywords: Edema; Enigma; 11 B-Hydroxysteroid Dehydrogenase Type 2; Sweetener "Stevia”

\section{Introduction}

11 Beta Hydroxysteroid Dehydrogenase Type 2 (11B-OSD2) is present in tissues with mineralocorticoid receptors such as renal parenchyma, colon and salivary gland and promotes the conversion of cortisol into cortisone [1-4]. The other isoenzyme type 1 , mainly located in the liver and adipose tissue facilitates conversion of cortisone into cortisol. Cortisol is an active mineralocorticoid with affinity similar to aldosterone in binding to mineralocorticoid receptor whereas cortisone is inactive [1-4]. Thus, these two isoenzymes preserve the delicate balance between cortisol and cortisone in the circulation and assist other mineralocoticcoids, e.g. aldosterone, in maintaining normal serum sodium and potassium concentrations via appropriate regulation of their excretion by the kidney resulting in maintainance of normal blood pressure [1-4].

Edema, Hypertension and Hypokalemia are well documented to occur with either the lack of 11B-HSD2 as a congenital defect or its inhibition induced by chronic ingestion of Licorice [1-8]. However, a similar occurrence following chronic use of sweetener "Stevia" is not described. Herein is a $1^{\text {st }}$ documentation of a subject presenting with edema, hypertension and hypokalemia induced by 11B-HSD2 inhibition by sweetener stevia.

\section{Case Report}

Thirty two year old Caucasian woman was referred to Endocrine Clinic for assessment of persistent edema of over 6 months' duration. Common causes of edema were excluded prior to referral by appropriate testing: Cardiac with normal ECG and Echocardiography; Hepatic with normal liver function tests including enzymes and normal hepatic architecture noted on abdominal ultrasound; Renal with normal serum urea nitrogen (SUN), creatinine (Creat), proteins and urinalysis without proteinuria.

Subject was requested to discontinue Furosemide and Potassium Chloride prescribed by Primary Care Provider over the telephone 3 weeks prior to clinic visit. The subject was not receiving any other medications, either by prescription or obtained over the counter from the pharmacy including contraceptives administered orally or via any other route. During the clinic visit, presence of pitting edema in both hands and feet was confirmed. Facial edema was also documented by a comparison with a photograph on driver's license obtained 3 years prior to visit. Body weight was $61 \mathrm{~kg}$, Blood pressure was 138/88 $\mathrm{mm} \mathrm{Hg}$ and radial pulse was regular 74/min (Table 1). Rest of the examinations including heart, lung, abdomen and neurological assessment were all unremarkable. 
Routine laboratory tests e.g., complete blood count, serum chemistries, Free T4 and TSH as well as 24 hour urinary creatinine and electrolytes were assessed by the clinical laboratory at a local medical center which also provided the normal ranges for these tests. Endocrine tests using both blood and urine were determined by a commercial laboratory (Quest Diagnostics, Chantily, Virginia, USA) which provided normal ranges for these tests. Complete Blood Count, Urinalysis, and Serum Urea nitrogen, Creatinine, Proteins, liver enzymes, Calcium, Phosphorus, lipid profile, Free T4 and TSH were all within normal range. Serum electrolytes are shown in Table 1. Serum aldosterone and upright plasma renin activity were both subnormal (Table 2). Therefore, the subject was recalled and requested to bring 24 hour urine sample for determination of creatinine, $\mathrm{Na}$, K, free cortisol and free cortisone. Blood was also withdrawn during this follow up clinic visit for determination of AM plasma cortisol and cortisone. AM plasma cortisol was within normal range but plasma cortisone was subnormal resulting in high plasma cortisol/cortisone ratio (Table 2). 24-hour urine creatinine excretion of $1.2 \mathrm{~g}$ was appropriate for assessing the adequacy of 24-hour urine collection. 24-hour urinary Na was appropriate for normal serum $\mathrm{Na}$, but 24-hour urine $\mathrm{K}$ was inappropriately elevated for corresponding serum K (Table 3). Simultaneously, 24-hour urine free cortisol was markedly elevated while 24-hour urinary free cortisone was extremely low (Table 3).

Therefore, the subject was contacted and questioned regarding ingestion of Licorice or a habit of chewing Tobacco since chewing tobacco is known to contain Licorice and chronic licorice ingestion is known to induce edema, hypertension and hypokalemia [1-8]. Subject denied either. However, on further repeated interrogation, the subject reported use of herbal sweetener "Stevia" powder for at least 9 months prior to initial clinic visit. $6 \mathrm{~g}-8 \mathrm{~g}$. were added to 4 to $6 \mathrm{oz}$ of coffee consumed 2 - 3 times a day. Moreover, the powder was also used in preparation of desserts consumed at least once a

Table 1. Pertinent endocrine tests prior to (pre) and after withdrawal (post) of stevia.

\begin{tabular}{cccc}
\hline & Pre & Post & Normal Range \\
\hline BW (KG) & 61 & 59 & - \\
BP (mmHg) & $138 / 88$ & $118 / 74$ & $<140 / 90$ \\
Pulse/Min & 78 & 74 & $60-90$ \\
Sodium (mM/L) & 141 & 140 & $135-145$ \\
Potassium (mM/L) & 3.4 & 4.2 & $3.5-5.0$ \\
Chloride (mM/L) & 95 & 101 & $99-107$ \\
HCO $_{3}(\mathrm{mM} / \mathrm{L})$ & 30 & 25 & $24-30$ \\
\hline
\end{tabular}

Table 2. Pertinent endocrine tests prior to (pre) and after withdrawal (post) of stevia.

\begin{tabular}{cccc}
\hline & Pre & Post & Normal Range \\
\hline $\begin{array}{c}\text { Plasma Renin } \\
\text { Activity (ng/ml·hr) }\end{array}$ & 0.4 & 2.2 & $0.29-3.7$ \\
$\begin{array}{c}\text { Serum } \\
\text { Aldosterone (ng/dl) } \\
\quad \text { Plasma } \\
\begin{array}{c}\text { Cortisol (ug/dl) } \\
\text { Plasma }\end{array}\end{array}$ & 8.6 & 6.8 & $3-10$ \\
Cortisone (ug/dl) \\
Cortisol/Cortisone
\end{tabular}

Table 3. 24 hour urine levels prior to (pre) and after withdrawal (post) of stevia.

\begin{tabular}{cccc}
\hline Urine Level & Pre & Post & Normal Range \\
\hline Sodium (mM/L) & 120 & 160 & $20-220$ \\
Potassium (mM/L) & 102 & 94 & $20-125$ \\
$\begin{array}{c}\text { Free Cortisol (ug/dl) } \\
\begin{array}{c}\text { Free Cortisone } \\
\quad(\text { ug/dl) }\end{array}\end{array}$ & 109 & 44 & $10-90$ \\
$\begin{array}{c}\text { Free Cortisol/Free } \\
\text { Cortisol }\end{array}$ & 78 & 5.5 & $<10$ \\
\hline
\end{tabular}

week. The subject was hence instructed to abstain from using stevia and substitute plain sugar instead for sweetening coffee and desserts. She was also requested to report for a follow up visit at 3 months with another 24 hour urine sample. During this visit, the subject reported a complete remission of edema since 2 weeks after discontinuation of stevia powder with confirmation on physical examination. Body weight was $57 \mathrm{~kg}$. Blood pressure was 118/74 mmHg with a regular pulse of 76/min (Table 1). Rest of the physical examination was again unremarkable. Blood was also withdrawn for determination of the same laboratory tests performed at the initial visit and showed normalization in serum $\mathrm{K}, \mathrm{Cl}$ and $\mathrm{HCO}_{3}$ (Table 1) as well as serum aldosterone, plasma renin activity, plasma cortisol and cortisone (Table 2).

Appropriate corresponding alterations were also noted in 24 hour urine $\mathrm{Na}, \mathrm{K}$, free cortisol and free cortisone concentrations (Table 3). Finally, a challenge with readministration of stevia powder to further establish its causative role in manifestations presented at the initial evaluation could not be conducted due to a vehement decline on the part of the subject. Moreover, the challenging process was not pursued also because of the ethical consideration in ensuing recurrence of clinical features with a special concern for induction of hypokalemia which could result in serious deleterious consequences, e.g. muscle weakness and/or paresis and cardiac 
arrhythmia. Therefore, we believe that onset of edema, prehypertension, and hypokalemia with a decline in both serum aldosterone and plasma renin activity and simultaneous increases in both plasma and urinary cortisol/ cortisone ratios were induced by chronic ingestion of sweetener stevia. Furthermore, normalization of all laboratory abnormalities and total remission of clinical manifestations following discontinuation indicates a distinct causative role of stevia in inhibition of 11 B hydroxysteroid dehydrogenase Type 2 .

\section{Discussion}

Edema, hypertension and hypokalemia have been well documented to occur in disorders with congenital deficiency or lack of 11 B Hyderoxysteriod Dehydrogenase Type 2 and its inhibition by chronic licorice ingestion, cushing syndrome secondary to ectopic ACTH secretion, acute alcoholism, chronic liver or renal disease, preeclampsia and/or pregnancy induced hypertension [1-16]. These clinical manifestations are attributed to enhanced retention of sodium and increased excretion of potassium by the kidney induced by markedly elevated plasma cortisol in the circulation. This case report demonstrates for the first time the role of "Stevia" sweetener in induction of the same manifestations by the same mechanism, e.g. inhibition of 11BOHSD2 as documented by subnormal serum aldosterone, low plasma rennin activity, marked elevations of both plasma cortisol/cortisone and 24 hour urinary free cortisol/free cortisone ratios. Furthermore, remission of manifestations following normalization of these laboratory abnormalities on abstinence from "Stevia” establishes its role as a causative factor.

The use of "Stevia" has apparently increased recently due to its publicity as a safe sweetener and its easy availability [17-19]. However, the data regarding effect of its chronic use in humans as well as animals is sparse in the literature. Some studies have reported improvement in hypertension whereas others have reported no benefit. Neither of these studies has reported changes in blood pressure in individual participant. Thus, it is plausible that in certain individual subjects, there may be a rise in blood pressure whereas in other participants, blood pressure may have declined as reported in some studies resulting in the lack of change in the entire population of subjects studied. None of the studies have reported clinical manifestations noted in our patient and none have studied its influence on renin angiotensin aldosterone axis or circulating cortisol or cortisone concentrations [17,20-25]. Occurrence of edema, rise in blood pressure, lowering of potassium and inhibition of renin angiotensin aldosterone axis by elevated cortisol/cortisone ratio indicating suppression of 11B-HSD2 noted in our subject in contrast to these studies may be attributed to several probable factors. Individual susceptibility due to genetic profile, the difference in the magnitude of the amount of daily ingestion, variable duration of ingestion, the differences in salt and water intake etc may have been responsible. However, the studies assessing effects of a single intravenous administration of the stevia extract or its chronic administration on renal water and electrolyte balance are sparse as well Thus, clinical and metabolic effects of variable daily dose as well as at variable periods during chronic administration of stevia requires further examination.

Therefore, in conclusion, this case report indicates that Stevia may induce edema, hypertension and hypokalemia via reduced conversion of cortisol into cortisone by inhibition of 11 B-Hydroxysteroid Dehydrogenase Type 2.

\section{REFERENCES}

[1] S. Ulick and R. Tedde, "Pathogenesis of the Type 2 Variant of the Syndrome of Apparent Mineralocorticoid Excess,” Journal of Clinical Endocrinology and Metabolism, Vol. 70, No. 1, 1990, pp. 200-206. doi:10.1210/jcem-70-1-200

[2] M. Shimojo and P. M. Stewart, "Apparent Mineralocorticoid Excess Syndromes,” Journal of Endocrinological Investigation, Vol. 18, No. 7, 1995, pp. 518-532.

[3] R. C. Wilson, S. Nimkarn and M. I. New, “Apparent Mineralocorticoid Excess,” Trends in Endocrinology \& Metabolism, Vol. 12, No. 3, 2001, pp. 104-111. doi:10.1016/S1043-2760(00)00356-8

[4] M. Quinkler and P. M. Stewart, "Hypertension and the Cortisol-Cortisone Shuttle,” Journal of Clinical Endocrinology and Metabolism, Vol. 88, No. 6, 2003, pp. 23842392. doi:10.1210/jc.2003-030138

[5] B. R. Walker, J. C. Campbell, R. Fraser, P. M. Stewart, C. R. Edwards, P. M. Stewart, et al., "Mineralocorticoid Activity of Liquorice: 11-Beta-Hydroxysteroid Dehydrogenase Deficiency, Comes of Age,” Lancet, Vol. 2, No. 8563, 1987, pp. 821-824.

[6] R. V. Farese Jr., E. G. Biglieri, C. H. Shackleton, I. Irony and R. Gomez-Fontes, "Licorice-Induced Hypermineralo Corticoidism," The New England Journal of Medicine, Vol. 325, No. 17, 1991, pp. 1223-1227. doi:10.1056/NEJM199110243251706

[7] Y. Kageyama, H. Suzuki and T. Saruta, "Glycyrrhizin Induces Mineralocorticoid Activity through Alterations in Cortisol Metabolism in the Human Kidney," Journal of Endocrinology, Vol. 135, No. 1, 1992, pp. 147-152. doi:10.1677/joe.0.1350147

[8] H. A. Sigurjonsdottir, J. Ragnarsson, L. Franzson and G. Sigurdsson, "Is Blood Pressure Commonly Raised by Moderate Consumption of Liquorice?” Journal of Human Hypertension, Vol. 9, No. 5, 1995, pp. 345-348.

[9] B. R. Walker, J. C. Campbell, R. Fraser, P. M. Stewart and C. R. Edwards, "Mineralocorticoid Excess and Inhibition of 11 Beta-Hydroxysteroid Dehydrogenase in Patients with Ectopic ACTH Syndrome," Clinical Endocrinology (Oxford), Vol. 37, No. 6, 1992, pp. 483-492. 
doi:10.1111/j.1365-2265.1992.tb01478.X

[10] P. M. Stewart, B. R. Walker, G. Holder, D. O’Halloran and C. H. Shackleton, "11 Beta-Hydroxysteroid Dehydrogenase Activity in Cushing's Syndrome: Explaining the Mineralocorticoid Excess State of the Ectopic Adrenocorticotropin Syndrome," Journal of Clinical Endocrinology and Metabolism, Vol. 80, No. 12, 1995, pp. 36173620. doi:10.1210/jc.80.12.3617

[11] M. Quinkler, S. Johanssen, C. Grossmann, V. Bähr, Müller, W. Oelkers and S. Diederich, "Progesterone Metabolism in the Human Kidney and Inhibition of 11 Beta-Hydroxysteroid Dehydrogenase Type 2 by Progesterone and Its Metabolites," Journal of Clinical Endocrinology and Metabolism, Vol. 84, No. 11, 1999, pp. 41654171. doi:10.1210/jc.84.11.4165

[12] E. Schoof, M. Girstl, W. Frobenius, M. Kirschbaum, H. G. Dörr, W. Rascher and J. Dötsch, "Decreased Gene Expression of 11 Beta-Hydroxysteroid Dehydrogenase Type 2 and 15-Hydroxyprostaglandin Dehydrogenase in $\mathrm{Hu}-$ man Placenta of Patients with Preeclampsia,” Journal of Clinical Endocrinology and Metabolism, Vol. 86, No. 3, 2001, pp. 1313-1317. doi:10.1210/jc.86.3.1313

[13] P. Heilmann, E. Buchheim, J. Wacker and R. Ziegler, "Alteration of the Activity of the 11 Beta-Hydroxysteroid Dehydrogenase in Pregnancy: Relevance for the Development of Pregnancy-Induced Hypertension?” Journal of Clinical Endocrinology and Metabolism, Vol. 86, No. 11, 2001, pp. 5222-5226. doi:10.1210/jc.86.11.5222

[14] B. Lanz, B. Kadereit, S. Ernst, K. Shojaati, M. Causevic, B. M. Frey, F. J. Frey and M. G. Mohaupt, “Angiotensin II Regulates 11 Beta-Hydroxysteroid Dehydrogenase Type 2 via AT2 Receptors,” Kidney International, Vol. 4, No. 3, 2003, pp. 970-977. doi:10.1046/j.1523-1755.2003.00192.x

[15] A. T. Stauffer, M. K. Rochat, B. Dick, F. J. Frey and A. Odermatt, "Chenodeoxycholic Acid and Deoxycholic Acid Inhibit 11 Beta-Hydroxysteroid Dehydrogenase Type 2 and Cause Cortisol-Induced Transcriptional Activation of the Mineralocorticoid Receptor," The Journal of Biological Chemistry, Vol. 277, No. 29, 2002, pp. 2628626292. doi:10.1074/jbc.M201556200

[16] C. A. Carvajal, D. G. Romero, L. M. Mosso, A. A. González, C. Campino, J. Montero and C. E. Fardella, "Biochemical and Genetic Characterization of 11 Beta-Hydroxysteroid Dehydrogenase Type 2 in Low-Renin Essential Hypertensives,” Journal of Hypertension, Vol. 23, No. 1, 2005, pp. 71-77. doi:10.1097/00004872-200501000-00015

[17] R. M. Oliveira-Filho, O. A. Uehara, C. A. Minetti and L. B. Valle, "Chronic Administration of Aqueous Extract of Stevia Rebaudiana (Bert.) Bertoni in Rats: Endocrine Ef- fects,” General Pharmacology, Vol. 20, No. 2, 1989, pp. 187-191. doi:10.1016/0306-3623(89)90013-X

[18] E. Koyama, K. Kitazawa, Y. Ohori, O. Izawa, K. Kakegawa, A. Fujino and M. Ui, "In Vitro Metabolism of the Glycosidic Sweeteners, Stevia Mixture and Enzymatically Modified Stevia in Human Intestinal Microflora," Food and Chemical Toxicology, Vol. 41, No. 3, 2003, pp. 359374. doi:10.1016/S0278-6915(02)00235-1

[19] E. Koyama, N. Sakai, Y. Ohori, K. Kitazawa, O. Izawa, K. Kakegawa, A. Fujino and M. Ui, “Absorption and Metabolism of Glycosidic Sweeteners of Stevia Mixture and Their Aglycone, Steviol, in Rats and Humans,” Food and Chemical Toxicology, Vol. 41, No. 6, 2003, pp. 875-883. doi:10.1016/S0278-6915(03)00039-5

[20] M. S. Melis, "Effect of Crude Extract of Stevia Rebaudiana on Renal Water and Electrolytes Excretion," Phytomedicine, Vol. 6, No. 4, 1999, pp. 247-250. doi:10.1016/S0944-7113(99)80016-6

[21] P. Chan, B. Tomlinson, Y. J. Chen, J. C. Liu, M. H. Hsieh and J. T. Cheng, "A Double-Blind Placebo-Controlled Study of the Effectiveness and Tolerability of Oral Stevioside in Human Hypertension," British Journal of Clinical Pharmacology, Vol. 50, No. 3, 2000, pp. 215220. doi:10.1046/j.1365-2125.2000.00260.x

[22] M. H. Hsieh, P. Chan, Y. M. Sue, J. C. Liu, T. H. Liang, T. Y. Huang, B. Tomlinson, M. S. Chow, P. F. Kao and Y. J. Chen, "Efficacy and Tolerability of Oral Stevioside in Patients with Mild Essential Hypertension: A Two-Year, Randomized, Placebo-Controlled Study," Clinical Therapeutics, Vol. 25, No. 11, 2003, pp. 2797-2808. doi:10.1016/S0149-2918(03)80334-X

[23] L. A. Ferri, W. Alves-Do-Prado, S. S. Yamada, S. Gazola, M. R. Batista and R. B. Bazotte, "Investigation of the Antihypertensive Effect of Oral Crude Stevioside in Patients with Mild Essential Hypertension,” Phytotherapy Research, Vol. 20, No. 9, 2006, pp. 732-726. doi:10.1002/ptr.1944

[24] K. C. Maki, L. L. Curry, M. C. Carakostas, S. M. Tarka, M. S. Reeves, M. V. Farmer, J. M. McKenney, P. D. Toth, S. L. Schwartz, B. C. Lubin, M. R. Dicklin, A. C. Boileau and J. D. Bisognano, "The Hemodynamic Effects of Rebaudioside A in Healthy Adults with Normal and LowNormal Blood Pressure," Food and Chemical Toxicology, Vol. 46 No. 7, 2008, pp. S40-S46. doi:10.1016/j.fct.2008.04.040

[25] M. S. Melis, "Chronic Administration of Aqueous Extract of Stevia Rebaudiana in Rats: Renal Effects," Journal of Ethnopharmacology, Vol. 47, No. 3, 1995, pp. 129-134. doi:10.1016/0378-8741(95)01271-Edoi:10.1089/thy.2007 .0222 